\title{
Vegetation dynamics and climate change on the Loess Plateau, China: 1982-2011
}

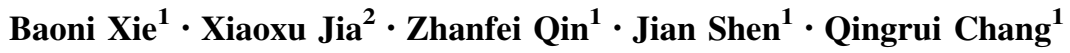

Received: 27 October 2014/ Accepted: 7 October 2015/Published online: 12 December 2015

(C) Springer-Verlag Berlin Heidelberg 2015

\begin{abstract}
Monitoring the dynamics of vegetation growth and its response to climate change is important to understand the mechanisms underlying ecosystem behaviors. This study investigated the relationship between vegetation growth and climate change during the growing seasons on the Loess Plateau in China by analyzing the normalized difference vegetation index (NDVI) derived from the Land Long Term Data Record dataset from 1982 to 2011. Results showed that growing-season NDVI had increased at an annual rate of 0.0028 , particularly in the semi-arid and semi-humid regions. By contrast, the NDVI first increased from 1982 to $1994\left(0.0013\right.$ year $\left.^{-1}, P<0.05\right)$ and then decreased from 1994 to 2011 (0.0016 year ${ }^{-1}$,
\end{abstract}

Editor: Xiangzheng Deng.

Electronic supplementary material The online version of this article (doi:10.1007/s10113-015-0881-3) contains supplementary material, which is available to authorized users.

\footnotetext{
Qingrui Chang

changqr@nwsuaf.edu.cn

Baoni Xie

chenshu0305@gmail.com

Xiaoxu Jia

jiaxx@igsnrr.ac.cn

Zhanfei Qin

zhanfeiqin@gmail.com

Jian Shen

jshen28@hotmail.com

1 College of Natural Resources and Environment, Northwest A\&F University, 3 Taicheng Road, Yangling 712100, China

2 Key Laboratory of Ecosystem Network Observation and Modeling, Institute of Geographic Sciences and Natural Resources Research, Chinese Academy of Sciences, No. 11, Datun Road, Chaoyang District, Beijing 100101, China
}

$P<0.05)$ in the arid region. Temperature had a positive effect on NDVI in most periods within and across seasons in the semi-humid region but had no significant effect in the arid region. Precipitation had a positive effect on NDVI in the arid region in summer and in the semi-arid region in autumn. Summer precipitation was important for autumn vegetation growth in the arid region, whereas summer temperature increased autumn vegetation growth in the semi-arid and semi-humid regions. Further analyses supported the lag-time effects of climate change on vegetation growth on the Loess Plateau. Precipitation shifts had 15- to 18-month time lag effects on vegetation growth in the three climate regions. Vegetation NDVI had a 17-month lag response to temperature in the semi-arid region. Human activities should not be neglected in analyzing the relationship between vegetation growth and climate change on the Loess Plateau.

Keywords LTDR - Normalized difference vegetation index (NDVI) - Precipitation · Temperature · Human activities · Loess Plateau

\section{Introduction}

Knowledge of the effects of climate change on vegetation growth is essential to understand the mechanisms underlying ecosystem behaviors and activities because vegetation plays an important role in linking soil, atmospheric, hydrological, and other elements of the biosphere together (Cao and Woodward 1998). Many recent analyses of satellite images have revealed temporal changes in vegetation growth and their relationship with climate change at both global (De Jong et al. 2012; Nemani et al. 2003) and continental (Gong and Shi 2003; Lucht et al. 2002; Myneni 
et al. 1997) scales. The response of vegetation growth to climatic changes differs widely by bioregion (Verbyla 2008) and biome (Jobbagy et al. 2002; Paruelo and Lauenroth 1995; Piao et al. 2006b). However, information on how climatic changes have influenced the growth of vegetation in relatively dry regions (Mohammat et al. 2013), such as the Loess Plateau in China, is lacking (Wang et al. 2011b). This lack of knowledge increases the uncertainties in the predictions of future trends of vegetation growth and may limit the accuracy of the ecosystem models at regional and global scales.

The Loess Plateau has the most severe soil erosion in the world, causing the region to be ecologically fragile (Han et al. 2010). The terrestrial ecosystems in this region therefore exhibit a comparatively sensitive response to climatic changes (Shi and Shao 2000). The vegetation on the plateau is important in mitigating soil erosion (Zhou et al. 2006). The regional mean annual temperature (MAT) has been shown to have significantly increased by $1.9{ }^{\circ} \mathrm{C}$ from 1961 to 2010 (Wang et al. 2012). Rising temperature may shift plant phenology (e.g., the timing of flowering and other developmental events) (Cleland et al. 2007; Jeong et al. 2011) and influence primary production and consequently ecosystem services (Feng et al. 2013).

Existing studies have revealed that vegetation activity at the middle-to-high latitudes in the northern hemisphere, where the Loess Plateau is located, has increased significantly since 1980 s, and global warming has prolonged the growing season in spring and autumn (Cong et al. 2013; Keeling et al. 1996; Kimball et al. 2004; Piao et al. 2006a; Zhang et al. 2013). Madelene and Chen (2006) reported that the regional changes in the vegetation of Ansai County on the Loess Plateau were mainly driven by the temperatures during the previous 6 months. The precipitation on the plateau has not significantly changed; thus, rapid warming could increase the loss of water from the land surface by increasing evaporation and thereby increase drought stress (Barber et al. 2000). Xin et al. (2008) suggested that precipitation limited the growth of vegetation on the plateau. Zhang et al. (2006) showed that water and temperature on the plateau are important along both latitudinal and longitudinal gradients. Vegetation growth trends have changed significantly in many parts of the plateau over the last three decades (Miao et al. 2012; Xin et al. 2008); thus, understanding the responses of vegetation growth to climatic changes is critical and so is predicting the future interactions between the terrestrial ecosystems and the climate system in this region.

The Loess Plateau spans diverse bioclimatic zones (Feng et al. 2013), and the response of the vegetation on the plateau to climate change may vary across these zones. In addition, seasonal information must also be considered and interpreted cautiously when analyzing the link between vegetation and climate (Piao et al. 2004). However, only a few studies have examined the temporal changes in the vegetation growth on the Loess Plateau and their relationship with the climate change across the seasons and climatic zones on the plateau. An elucidation of the spatiotemporal changes in the vegetation growth throughout the plateau and the climatic drivers behind such changes will result in a better understanding of how vegetation growth reacts to warming and/or drying in the future.

Satellite imaging has become an effective tool of ecological scientists in monitoring the seasonal and inter-annual vegetation dynamics. The normalized difference vegetation index (NDVI), which is the nonlinear combination of near-infrared (NIR) and red spectral reflectance $[(\mathrm{NIR}-\mathrm{RED}) /(\mathrm{NIR}+\mathrm{RED})]$, is considered to be a good indicator of green biomass and is commonly used to detect long-term variations in vegetation (De Jong et al. 2012; Tucker 1979). The Land Long Term Data Record (LTDR) dataset is the most recent NDVI dataset and the first component of a cross-sensor long-term NDVI record [which was continued by Moderate Resolution Imaging Spectroradiometer (MODIS) and Visible Infrared Imaging Radiometer Suite (VIIRS)] (Pedelty et al. 2007; Wang et al. 2008). The LTDR dataset is thus expected to be a promising substitute for earlier datasets (Alcaraz-Segura et al. 2010).

The Loess Plateau was partitioned into three climate regions, namely arid, semi-arid, and semi-humid regions (Zheng et al. 2010), to understand the relationship between the vegetation growth and climatic variables more comprehensively. This study aims to (1) investigate the spatiotemporal changes in the vegetation growth during the growing season from 1982 to 2011 throughout the Loess Plateau and (2) analyze the relationships between vegetation growth, precipitation, and temperature in different growing seasons and climate regions during the last three decades.

\section{Study area}

The Loess Plateau $\left(34^{\circ}-45^{\circ} 5^{\prime} \mathrm{N}, 101^{\circ}-114^{\circ} 33^{\prime} \mathrm{E}\right)$ is located in the upper and middle reaches of the Yellow River in China and has an area of approximately $640,000 \mathrm{~km}^{2}$ (Fig. 1a). It covers most parts of the provinces of Gansu, Shaanxi, and Shanxi, as well as the autonomous region of Ningxia Hui, and parts of Qinghai, Henan, and Inner Mongolia. The depths of its ancient loessial deposits range from 30 to $80 \mathrm{~m}$ (Wang et al. 2011b). Its undulating terrain varies in elevation between 200 and $3000 \mathrm{~m}$. Its climate has typical continental characteristics and can be subcategorized as arid, semi-arid, and semi-humid (warm and temperate) continental climatic zones from northwest to 

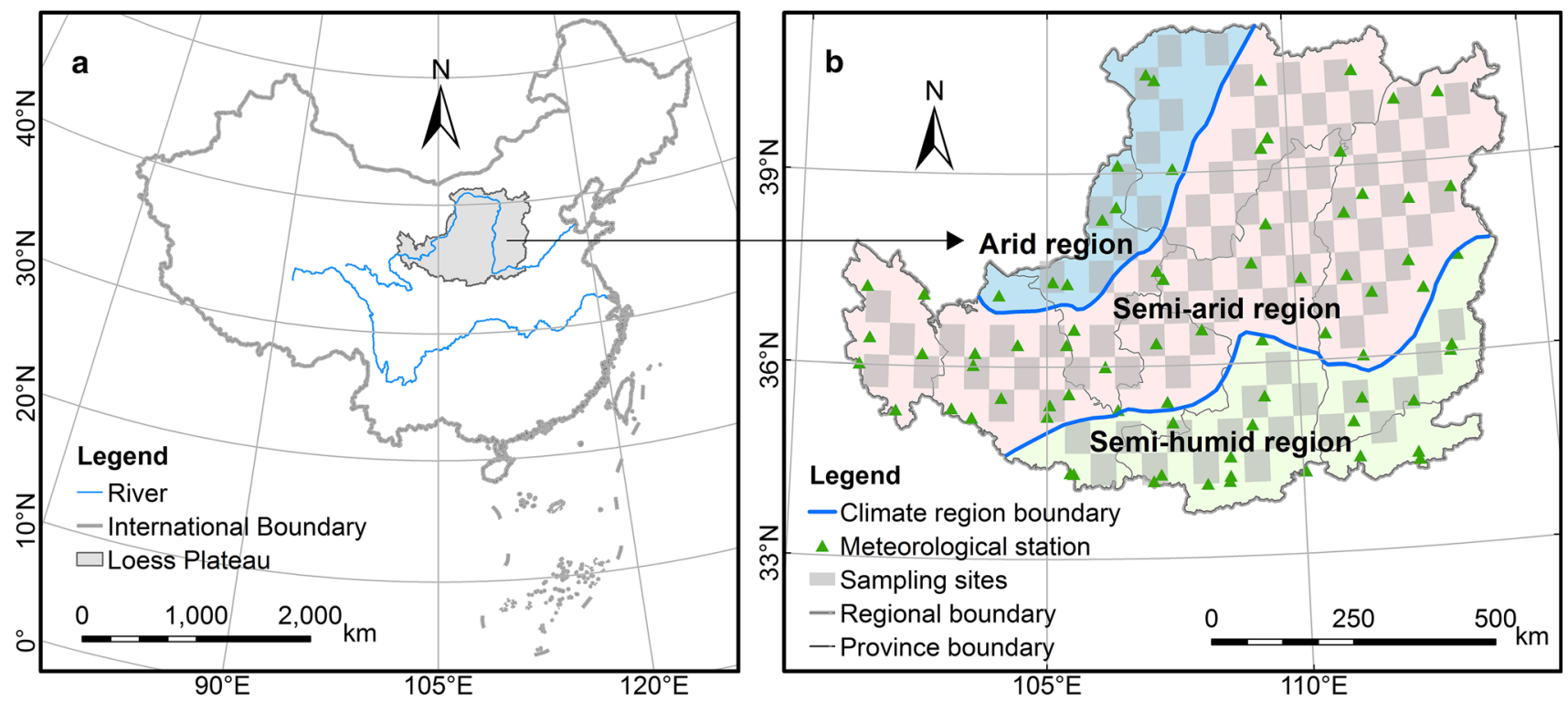

Fig. 1 Geographical maps of the Loess Plateau: a location of the plateau, b 64 weather stations, 89 sampling sites, and 3 climate regions in the study area

southeast. The MAT and mean annual precipitation (MAP) during the study period (1982-2011) followed the latitudinal and longitudinal gradients from the arid region to the semi-humid region (Fig. A1b, c). The arid region has the driest and coolest climate (MAP $<300 \mathrm{~mm}$ and MAT $=7.5^{\circ} \mathrm{C}$ ), whereas the semi-humid region has the wettest and warmest climate (MAP $>500 \mathrm{~mm}$ and MAT $\left.>10{ }^{\circ} \mathrm{C}\right)$. The semi-arid region has a moderate climate and covers the largest area of the plateau ( $63 \%$ of the study area). The vegetation within each of the three zones is recognized based on the national vegetation regionalization system (Wu 1982): desert, temperate steppe, and warm temperate deciduous broad-leaved forest (from north to south). The average NDVI during the growing season has a spatial gradient similar to the precipitation gradient (Fig. A1a). The NDVI values in the forested areas in Shanxi and Shaanxi are above 0.6, and the NDVI values in the grasslands in the arid and semi-arid regions are below 0.4 .

\section{Datasets and methods}

\section{Datasets}

\section{Remotely sensed dataset}

Data from the latest NDVI dataset, which is LTDR, were employed in this study. LTDR, which is a part of the Research, Education, and Applications Solutions Network project of the Earth Science Division of National Aeronautics and Space Administration (NASA), was launched to monitor global climate change and the corresponding reactions of terrestrial ecosystems. The aim of the LTDR project was to develop and produce global coincident, long-term, coarse spatial resolution $\left(0.05^{\circ}\right)$ data from the Advanced Very High Resolution Radiometer (AVHRR), MODIS, and VIIRS sensors. This project has reprocessed global area coverage data from the different platforms of the National Oceanic and Atmospheric Administration (NOAA) since 1981 by applying MODIS-like processing methods with a systematic quality assessment (Pedelty et al. 2007). The LTDR products provided daily surface reflectance and NDVI datasets. We used the LTDR V3 NDVI daily data from 1981 to 2011. A variety of processing techniques were implemented on the dataset, such as orbit calibration, sensor calibration, cloud screening, georeferencing correction, atmospheric correction (Rayleigh scattering, ozone, water vapor, and aerosols), and bidirectional reflectance distribution function normalization (Pedelty et al. 2007; Vermote and Saleous 2006).

\section{Climatic datasets}

Monthly temperature and precipitation and daily temperature datasets were acquired from the China Meteorological Data Sharing Service System (http://data.cma.gov.cn/). The monthly climatic dataset contains climatic data from 73 stations, 64 of which were selected according to the standards of the European Climate Assessment (Albert Klein et al. 2002). The locations of the weather stations on the Loess Plateau are shown in Fig. 1b. The daily temperature dataset is the reanalysis product that has sub-daily temporal resolution available from 1961 to the present and a spatial resolution of $0.5^{\circ}$. 
Inverse distance weighting (IDW) and ordinary Kriging methods are widely used methods for the interpolation of climatic data (Cai et al. 2005). To choose the most suitable method for this study, we randomly selected 1-month climatic data (April, 2008) to evaluate the estimated surfaces using a cross-validation approach (Kurtzman and Kadmon 1999). Finally, the IDW approach was chosen to interpolate the climatic data into continuous surfaces with the same temporal and spatial resolutions as those of the NDVI data to ensure better correlation coefficients between the observed and the predicted climate variables.

\section{Data analysis}

The maximum-value composite method, which can reduce the effects of atmospheric and cloud contamination (Holben 1986), was used to composite the monthly LTDR NDVI data. NDVI values ranged between -1 and 1 , and the values lower than 0.2 represent sparsely vegetated or unvegetated areas, such as barren lands (rock or soil), water, snow, ice, and clouds. Only pixels with yearly mean values lower than 0.1 were excluded from the analysis to ensure the inclusion of sparsely vegetated areas in the analysis (De Jong et al. 2012). The scale of the study area is regional, and we divided the study area into three climate regions; thus, we formulated definitions based on the local vegetation phenology instead of using the general definitions used for continental and hemispheric scales. We selected $5{ }^{\circ} \mathrm{C}$ as the temperature threshold for our growingseason definition for each climate region on the Loess Plateau. The annual length of the growing season is defined as the number of days between the first span of at least 5 days with a daily mean temperature warmer than $5{ }^{\circ} \mathrm{C}$ and the first span of 5 days with a daily mean temperature below $5{ }^{\circ} \mathrm{C}$ (Nemani et al. 2003). From this definition, the growing seasons in the arid and semi-arid regions were from April to October, whereas that in the semi-humid region was from March to November. The NDVI in the growing season was calculated by the average monthly NDVIs from April to October in the arid and semi-arid regions and from March to November in the semi-humid region. The seasonal NDVIs in spring (April and May in the arid and semi-arid regions and from March to May in the semi-humid region), summer (June-August in all three climate regions), and autumn (September and October in the arid and semi-arid regions and from September to November in the semi-humid region) were calculated as the average NDVI during the corresponding months (Wang et al. 2011a). The final dataset contained 25,184 unmasked pixels that covered $99.15 \%$ of the Loess Plateau. The data from 1981 were missing, however; thus, the year was excluded from the analysis. Missing data from 1994 (October-December) were estimated using the mean NDVI value for the corresponding months in 1993 and 1995. A final group of 360 images of NDVI values with a frequency of 12 images per year were composited.

Linear least-squares regression was applied to calculate the variation in the NDVI and climatic values for each grid point (Cong et al. 2013) and climate region to determine the trends of NDVI, temperature, and precipitation in the time series (1982-2011):

$T=\frac{n \times \sum_{i=1}^{n}\left(i \times Y_{i}\right)-\sum_{i=1}^{n} i \sum_{i=1}^{n} Y_{i}}{n \times \sum_{i=1}^{n} i^{2}-\left(\sum_{i=1}^{n} i\right)}$

where $T$ is the trend of NDVI, temperature, or precipitation; $i$ is the year from 1 to $n ; n$ is the number of years; $Y_{i}$ is the seasonal NDVI, temperature, or precipitation of year $i$. A positive value of $T$ indicates an increase in the NDVI, temperature, or precipitation in a time series. A $P$ value of less than 0.05 was considered significant.

We then analyzed the effects of seasonal temperature and precipitation on the trends of vegetation change in different seasons and climate regions by conducting a partial correlation analysis to eliminate the effects of other variables. To reduce computational time, we used sampling grids consisting of 89 sites that are centered at the interaction points, each covering an area of $0.5^{\circ} \times 0.5^{\circ}$. The final samples of arid, semi-arid, and semi-humid regions were 11,60 , and 18 , respectively. The sampling sites are illustrated in Fig. 1b. The trend and correlation analyses were conducted in $\mathrm{R}$ program ( $\mathrm{R}$ 2015).

\section{Results}

\section{Annual changes in NDVI during growing season}

\section{Changes in NDVI on the entire Loess Plateau}

The spatial patterns of the trend of the mean growingseason NDVI from 1982 to 2011 are shown in Fig. 2. A significant increase in growing-season NDVI at a rate of 0.0028 year $^{-1}$ was detected throughout the entire study period $(r=0.86, P<0.001)$. The trend of the vegetation growth across the plateau was heterogeneous. Most of the area $(78 \%$ of the whole study area, Fig. 2a) had an increasing trend in growing-season NDVI, which was statistically significant $(P<0.05)$ over $66 \%$ of the area and was concentrated mainly in areas where MAP was higher than $400 \mathrm{~mm}$ (Figs. 2b, A1c). The Loop Plain in Inner Mongolia and Ningxia, where MAP was lower than $400 \mathrm{~mm}$, also had an increasing trend in growing-season NDVI. Growing-season NDVI decreased significantly mainly in grasslands and sparsely vegetated areas (9\% of the study area) in northwestern Inner Mongolia, northern Ningxia, northern Gansu, and southwestern Qinghai 


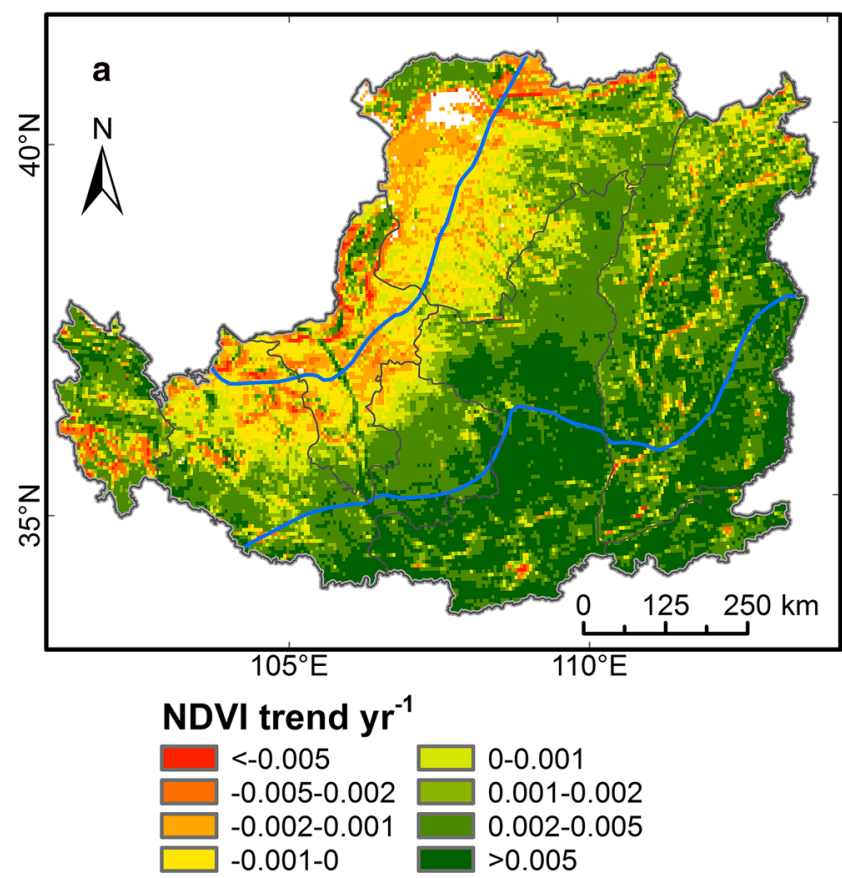

Fig. 2 Spatial distribution of NDVI trends on the Loess Plateau during the growing season in 1982-2011: a growing-season NDVI trend, b significance of growing-season NDVI trend. The blue lines

(Figs. 2, A1d). Temperature exhibited an increasing trend over the last three decades $\left(0.05{ }^{\circ} \mathrm{C}\right.$ year ${ }^{-1}, r=0.71$, $P<0.001$ ), similar to the trend in NDVI, whereas precipitation experienced a general nonsignificant decreasing trend in most areas of the Loess Plateau, with an average decreasing rate of $0.72 \mathrm{~mm}_{\text {year }}{ }^{-1}(r=0.12, P=0.54)$.

Numerous studies have indicated that the greening trend may not be continuous over some regions in the northern hemisphere (e.g., De Jong et al. 2012; Piao et al. 2011). A piecewise linear regression approach with one turning point (TP) was applied to the NDVI and climate time series in the three climate regions to find out whether the Loess Plateau is one of the regions. The results showed that growing-season NDVI is temporally homogeneous, increasing during the entire 30 years at the regional scale. The TP year of growingseason NDVI trend is 2000. The spatially averaged growingseason NDVI over Loess Plateau increased by 0.0014 year $^{-1}$ from 1982 to $2000(r=0.741, n=19, P<0.001)$ and significantly increased by 0.0058 year $^{-1}$ from 2000 to 2011 $(r=0.904, n=12, P<0.001)$.

\section{Changes in NDVI in different climate regions}

Figure 3 shows the changes in NDVI, temperature, and precipitation in three climate regions: arid, semi-arid, and semi-humid. The mean growing-season NDVI varied across climate regions. The NDVI in the semi-humid region increased at the highest annual rate of $0.0058(r=0.89$,

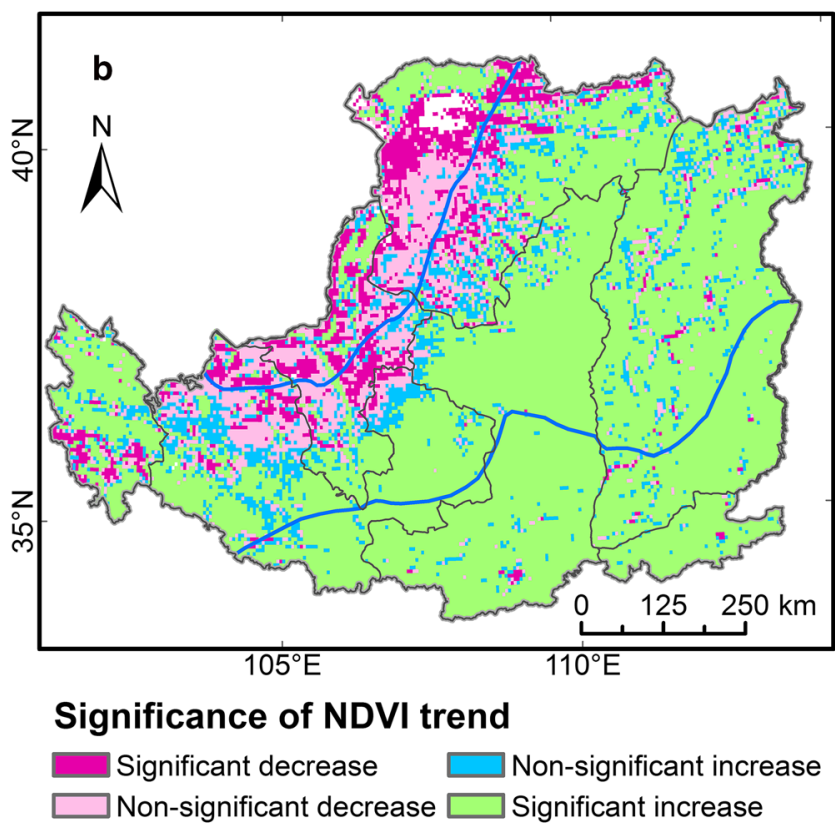

are the boundaries of the arid, semi-arid, and semi-humid climate regions (color figure online)

$P<0.001)$, followed by the NDVI in the semi-arid region, whose increasing rate was $0.0023(r=0.80, P<0.001)$ (Fig. 3d, g). The arid region experienced the smallest and weakest decreasing trend in NDVI during the study period (0.0003 year ${ }^{-1}, r=0.17, P=0.38$ ) (Fig. 3a).

The piecewise linear regression results showed that the TP years for the growing-season NDVIs in the arid, semi-arid, and semi-humid regions were 1994, 2001, and 1995, respectively (Fig. 3a, d, g). The growing-season NDVIs in both semi-arid and semi-humid regions slightly increased before TP (0.001 year ${ }^{-1}, r=0.48, n=20, P=0.05$; 0.0006 year $^{-1}, r=0.30, n=14, P=0.31$, respectively) and then both marginally increased after TP $\left(0.006\right.$ year $^{-1}$, $r=0.65, n=11, P<0.05 ; 0.01$ year $^{-1}, r=0.95, n=17$, $P<0.001$, respectively). Unlike the growing-season NDVIs in the semi-arid and semi-humid regions, the growing-season NDVI in the arid region increased at a rate of 0.0013 year $^{-1}$ before TP $(r=0.60, n=13, P<0.05)$, but decreased at a rate of 0.0016 year $^{-1}$ after TP $(r=0.57, n=18, P<0.05)$.

\section{Inter-annual correlation between NDVI and climate variables}

\section{Correlation between growing-season NDVI and climate}

Growing-season NDVI was correlated with temperature more strongly than precipitation across the entire plateau. More than $54 \%$ of the sampling grids (out of 89 samples) 

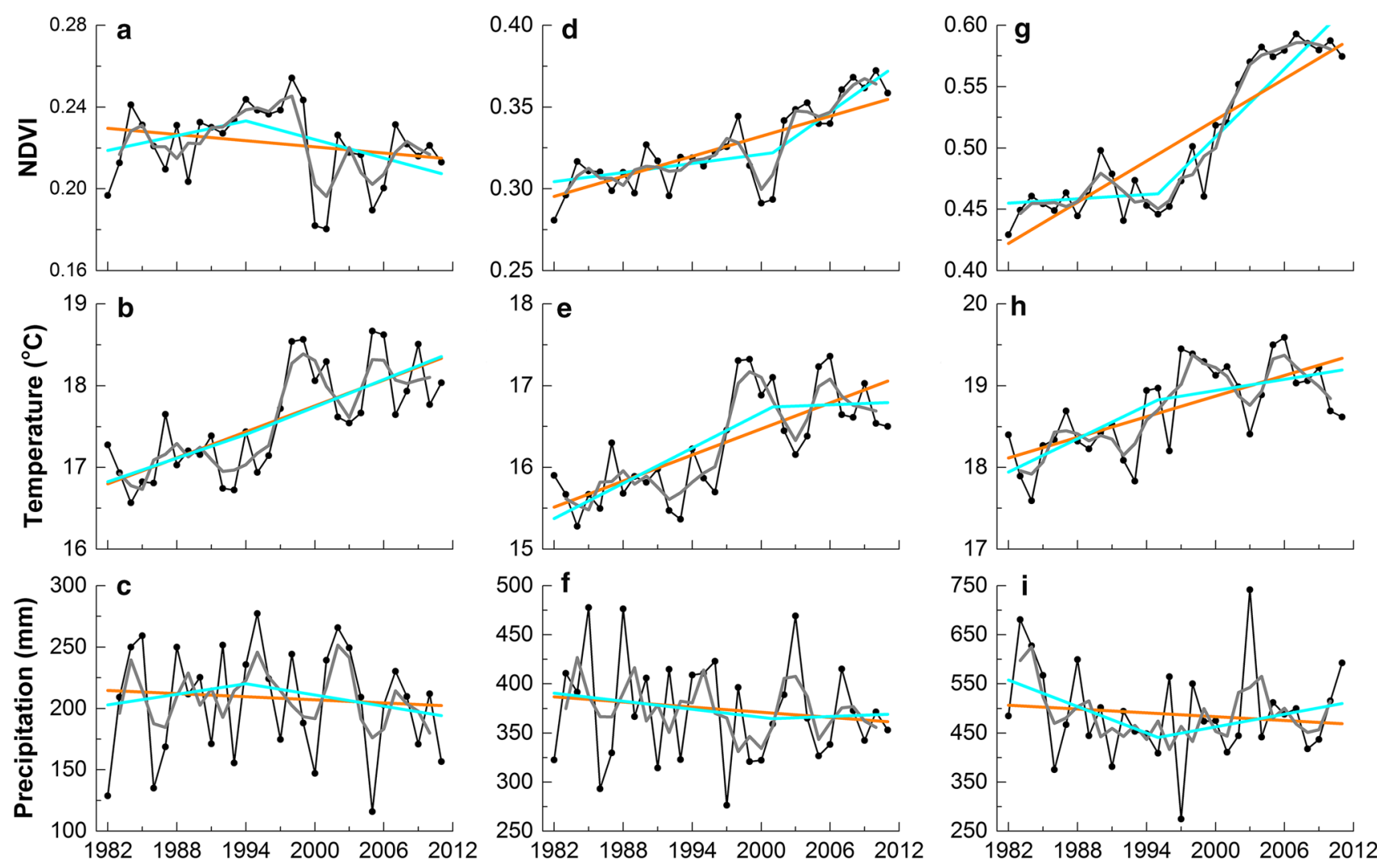

Fig. 3 Inter-annual variations in NDVI, temperature, and precipitation in the growing season in three climate regions on the Loess Plateau during 1982-2011: a-c arid region; d-f semi-arid region; g-i semi-humid region. The bold lines represent the 3-year running means. The blue lines and orange lines indicate the linear fits during the period before TP, the period after TP and during the period from 1982 to 2011, respectively (color figure online) showed that a positive correlation $(P<0.05)$ exists between growing-season NDVI and temperature. NDVI and precipitation were positively correlated in $39 \%$ of the sampling grids. Temperature may be a dominant factor controlling vegetation growth across most of the study area. More than $63 \%$ of the sampling grids exhibited larger correlation coefficients between NDVI and temperature than the correlation coefficients between NDVI and precipitation.

A clear regional contrast, however, existed between the dominant climatic variables underlying the detected changes in growing-season NDVI. In the arid region, NDVI was negatively correlated with temperature in $27 \%$ of the sampling grids and positively correlated with precipitation in $56 \%$ of the sampling grids (Fig. 4a, b), suggesting that rising temperature may suppress vegetation growth in areas with water shortage. Growing-season NDVI was positively correlated with precipitation and temperature in 45 and $33 \%$ of the sampling grids in the semi-arid region, respectively (Fig. 4c, d). All sampling grids exhibited a positive correlation between growing-season NDVI and temperature in the semi-humid region.

\section{Correlation between seasonal NDVI and climate}

Vegetation growth, however, may vary seasonally in response to climate change. We therefore examined the link between NDVI, temperature, and precipitation in spring, summer, and autumn across three climate regions. The NDVI-climate relationships were weaker in seasonal correlations (Fig. 4). Most sampling grids showed positive correlation coefficients between seasonal NDVI and climate variables, suggesting that rising temperature and precipitation would be beneficial to vegetation growth on the Loess Plateau. Among the sampling grids, 57 and $65 \%$ exhibited higher correlation coefficients between NDVI and precipitation than those between NDVI and temperature (53 and $35 \%$, respectively) in spring and autumn, suggesting that precipitation may be more important than temperature for driving the vegetation growth in these two seasons. Among the sampling grids, $53 \%$ indicated that NDVI was more strongly correlated with temperature than precipitation in summer.

In the arid region, NDVI showed a weak correlation with both temperature and precipitation in spring and 

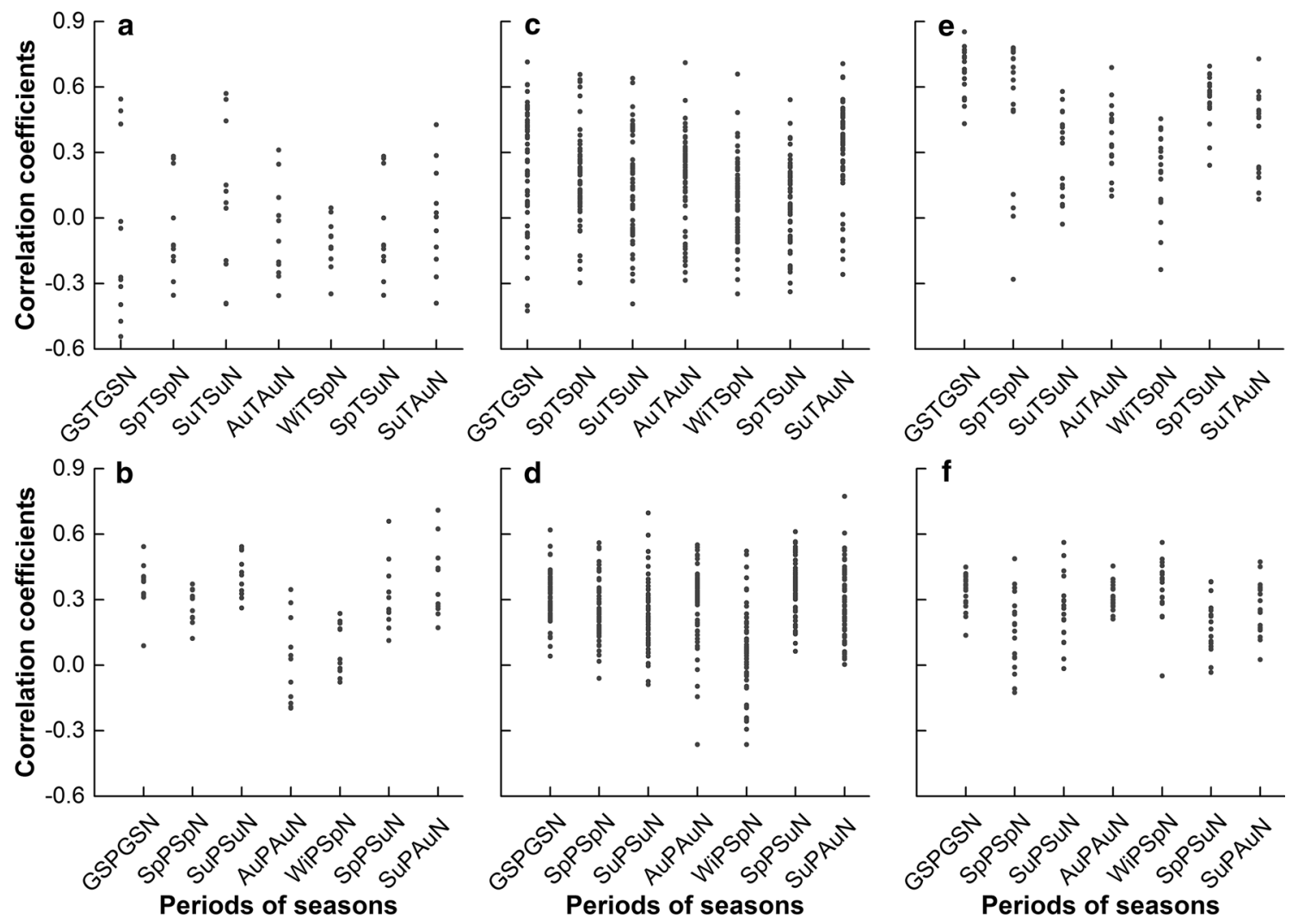

Fig. 4 Correlation coefficients between NDVI, temperature precipitation in the same and previous seasons in the different climate regions on the Loess Plateau in 1982-2011: a, b arid region; c, d semi-arid region; e, $\mathbf{f}$ semi-humid region. GS denotes growing season,

autumn (Fig. 4a, b). By contrast, precipitation was positively correlated with NDVI in summer (64\% of the sampling grids) in the arid region. NDVI and temperature were positively correlated in most of the sampling grids in all seasons in the semi-arid and the semi-humid regions (Fig. $4 \mathrm{c}$, e). The considerable area where the correlation coefficients between NDVI and precipitation were higher than those between NDVI and temperature in the semi-arid region in spring (67\% of the sampling grids) and autumn (78 \% of the sampling grids) indicates that precipitation may be the main driver of vegetation growth in the semiarid region (Fig. 4c, d). By contrast, temperature was the main driver in the semi-humid region in spring and autumn (Fig. 4e, f). The effects of temperature and precipitation on summer NDVI seem to be equivalent in semi-arid and semi-humid regions (the numbers of sampling grids controlled by temperature and precipitation exhibit a 1:1 ratio).

Some studies have reported an obvious seasonal lagtime effect between NDVI and climate variables (Chuai et al. 2013; Piao et al. 2006b; Xin et al. 2008); thus, we performed analyses between the seasonal NDVI and the climate variables in the previous seasons (Fig. 4). The lagtime effects of winter temperature on spring NDVI were
$\mathrm{Sp}$ denotes spring, $\mathrm{Su}$ denotes summer, $\mathrm{Au}$ denotes autumn, Wi denotes winter, $\mathrm{N}$ denotes NDVI, $\mathrm{T}$ denotes temperature, and $\mathrm{P}$ denotes precipitation. For example, SpNSuT stands for correlation coefficients between spring NDVI and summer temperature

not significant in most of the areas in the three regions. Significant positive lag-time effects of winter precipitation on spring NDVI were evident in the semi-humid region (56\% of the sampling grids). Spring precipitation was significantly positively correlated with summer NDVI in $27 \%$ of the arid region and $52 \%$ of the semi-arid region, whereas spring temperature was significantly correlated with summer NDVI in $89 \%$ of the semi-humid region. Strong lag-time effects of summer temperature on autumn NDVI existed in $57 \%$ of the semi-arid region and $61 \%$ of semi-humid region, whereas summer precipitation was crucial for autumn NDVI in $45 \%$ of the arid region.

As mentioned, spring and summer precipitations were both important for vegetation growth in the later seasons in the arid region, indicating that the lag time may be 3-6 months. Winter precipitation was important for vegetation growth in the later seasons in the semi-humid region, implying that the lag time may be 9 months. Therefore, the time period over which temperature and precipitation most strongly influence overall vegetation productivity on the Loess Plateau must be determined. We performed a series of correlation analyses based on the method proposed by Wang et al. (2003). Growing-season NDVI (e.g., April to 
October in 2008) was taken as one variable. The other variable was the period of climate variables (average temperature and accumulated precipitation); this period ranged from the current growing season (e.g., April to October in 2008) to the period of the previous year (e.g., March in 2008 to January in 2007), at increments of 1 month.

For the entire study area, the correlation coefficients between NDVI, temperature, and precipitation increased and peaked when the time interval reached 15 months (from October to August of the previous year). The correlation coefficients between NDVI and precipitation were strongest in the arid region and weakest in the semi-humid region (Fig. 5). Similar to the results on the entire Loess
Plateau, the strongest correlations between NDVI and precipitation were at an interval of 16 months in the arid region (from October to July of the previous year) and 15 months in the semi-arid region (from October to August of the previous year). By contrast, the strongest correlation coefficients between NDVI and precipitation were found at an interval of 16-19 months (from November to September-May of the previous year) in the semi-humid region. Lag-time effects between temperature and NDVI were not evident in the arid and semi-humid region. The strongest correlation between NDVI and temperature was noted when the temperature was integrated over a 15-month period (from October to August of the previous year) in the semi-arid region.
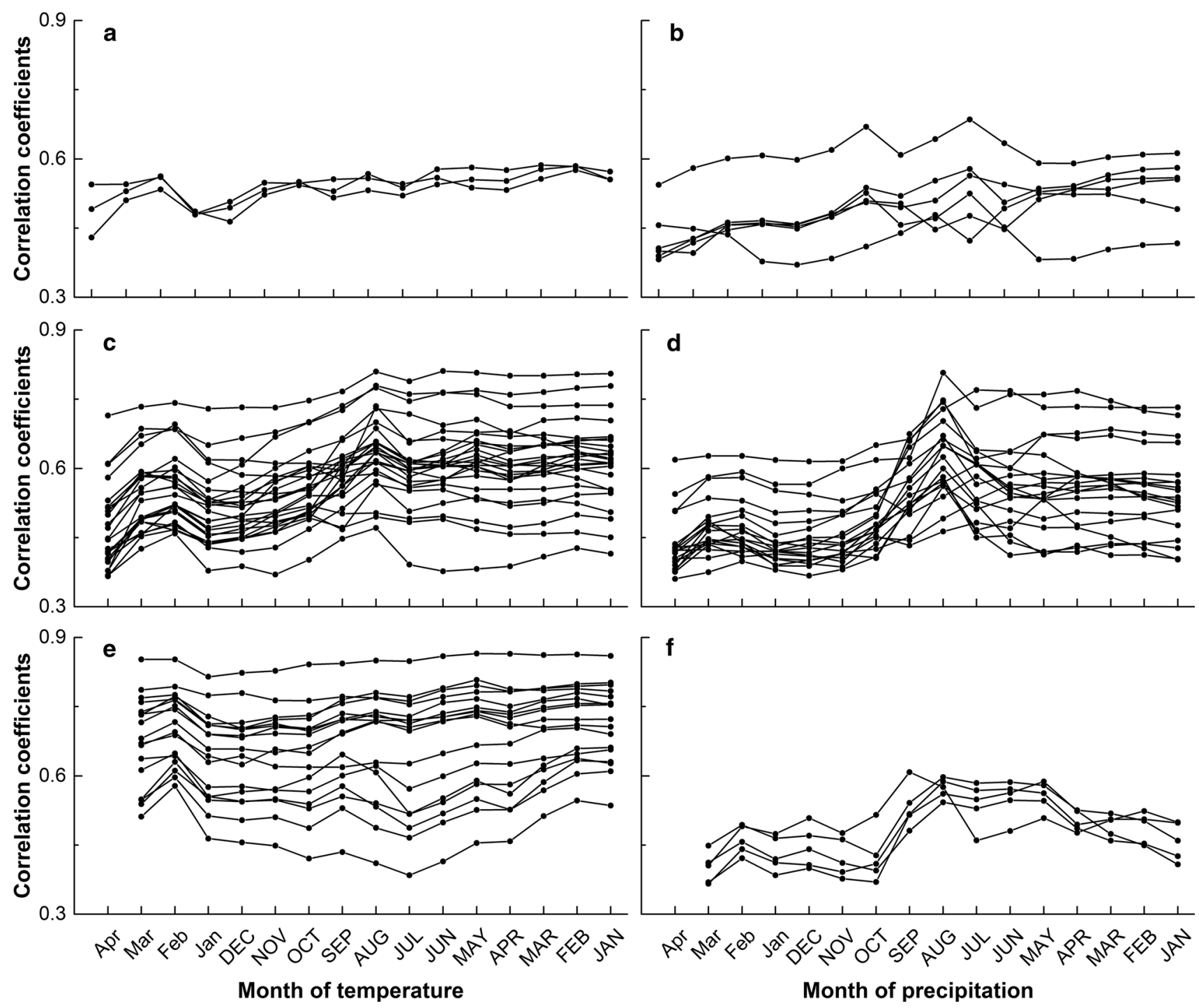

Fig. 5 Correlation coefficients between growing-season NDVI and previous season temperature and precipitation in three climate regions: a, b arid region; c, $\mathbf{d}$ semi-arid region; e, $\mathbf{f}$ semi-humid region. Abbreviated months in uppercase letters on the $x$-axes indicate the months of the previous year (only statistically significant correlation coefficients during all periods are shown.) 


\section{Discussion}

Plants in temperate regions commonly require a winter chilling period with a temperature below $5{ }^{\circ} \mathrm{C}$ for rapid budburst the following spring. The $5{ }^{\circ} \mathrm{C}$ temperature threshold was used to define the vegetation green-up and dormancy in each climate region in this study. The temperature threshold chosen in the present study is same as that determined by Prentice et al. (1992) but is lower than the temperature thresholds at the beginning and end of growing season (11.3 and $8.2{ }^{\circ} \mathrm{C}$, respectively) determined by Piao et al. (2006a) in China. Deviations may be caused by the differences in the required temperature thresholds of different vegetation types to trigger green-up; thus, differences in growing-season length also ensue. In future studies, different temperature thresholds may be used in conjunction with vegetation NDVI data for different vegetation types to extract phenology at the regional scale.

The NDVI for vegetation growth on the Loess Plateau generally increased in the growing seasons between 1982 and 2011 at an annual rate of 0.0028. Xin et al. (2008), however, reported that the vegetation cover increased in the 1980s, maintained a relatively steady state in the 1990s, rapidly decreased in 1999-2001, and then rapidly increased in 2002-2006 on the Loess Plateau. They used the maximum annual NDVI to represent the annual NDVI, whereas we adopted the average NDVI of the growing season for the current study. Growing-season NDVI increased in the semi-arid and semi-humid regions of the Loess Plateau and decreased in the arid region from 1982 to 2011 (Figs. 2, 3). The decreasing trend in the arid region might have been due to severe weather (MAP $<300 \mathrm{~mm}$ ) and the considerable lack of vegetation cover. The piecewise linear regression results showed that the TP of the growing-season NDVI trend in the arid, semi-arid, and semi-humid regions occurred in 1994, 2001, and 1995, respectively. This result was similar with that of Piao et al. (2011); from the results they obtained, the TP of growing-season NDVI on the Loess Plateau mostly occurred between 1992 and 1996. Our results also showed that the growing-season NDVI on the Loess Plateau increased slightly before TP and increased significantly after TP in most areas of the Loess Plateau, indicating that growing-season NDVI on the Loess Plateau was continuously increasing in most areas during the past three decades. Such vegetation growth pattern is different from those in North America (Wang et al. 2011a) and Eurasia (Piao et al. 2011), where vegetation greening trend is not continuous in most areas.

NDVI was negatively correlated with temperature both within the season and in previous seasons in the arid region (Fig. 4). Chuai et al. (2013) also found a negative correlation between NDVI and summer temperature for steppes and meadows in Inner Mongolia, where the type of vegetation is similar to that in the arid region defined in the current study. This vegetation growth response to climatic factors may explain the decline of vegetation in the arid region (Fig. 3a) in 1994-2011. Along with decreasing precipitation, increasing temperature can enhance evaporative demand which could lead to soil water deficits, which, in turn, could suppress vegetation growth (Barber et al. 2000; Dai et al. 2011).

Precipitation in arid regions was positively correlated with NDVI within and across seasons (Fig. 4). Spring precipitation is important for summer vegetation NDVI in the semi-arid region. Autumn NDVI was positively correlated with autumn and summer temperatures and precipitations in the semi-arid region; however, precipitation was more important, indicating that abundant precipitation was important for vegetation growth in relatively dry regions (Nemani et al. 2003; Xin et al. 2008; Zhao et al. 2011). Zhao et al. (2011) found a strong correlation between precipitation and change in NDVI in Xinjiang, a typical arid region in the northwestern part of the Loess Plateau. The dry weather and severe environmental conditions in this region may be responsible for the said NDVI-climate relationship. Sandstorms in the Kubuqi and Maowusu deserts reduced the vegetation cover $(\mathrm{NDVI}<0.3$, Fig. A1a); in these areas annual precipitation was below $300 \mathrm{~mm}$. Soil moisture, which is an important factor for vegetation growth, is directly influenced by precipitation, which, in turn, affects vegetation growth. Precipitation thus plays an important role in plant growth in arid and semiarid regions because it is the main source of soil moisture. However, our results showed that a $200-\mathrm{mm}$ precipitation threshold was found in the correlation between NDVI and precipitation. Thus, too little or too much precipitation both failed to raise the NDVI in dry regions. This inference suggests limited water-use capacity in dry regions (Piao et al. 2006b; Tucker et al. 1991). The relationship between the autumn climate and vegetation NDVI also suggested that the benefits of warming to autumn vegetation NDVI were not common in the semi-arid region. Mohammat et al. (2013) suggested that a change in the Palmer drought severity index (PDSI) in autumn regulated the autumn vegetation growth in central Asia, particularly in dry regions, such as the regions of the current study. The PDSI is based on a supply-and-demand model of soil moisture. Our results support their findings: Precipitation was the main source of soil water in semi-arid regions. Autumn precipitation increased in most areas of the semi-arid region from 1982 to 2011, particularly from 1992 to 2011 .

Temperature may be the main driver of vegetation growth in the semi-humid region. This relationship was evident within a season and in the previous seasons 
(Fig. 4) probably because the main vegetation type in the semi-humid region is cropland, which is mainly on relatively flat terrain where human interference (e.g., irrigation) is common; thus, crop growth seldom depends on precipitation (Miao et al. 2012). Temperature could thus be the limiting factor for vegetation growth. Notably, winter precipitations in most sampling grids $(56 \%)$ were positively correlated with spring NDVI in the semi-humid region, further proving the lag-time effects of winter precipitation on the spring green-up for vegetation. Winter snow helps to conserve soil moisture during long winter months. Nearly all the moisture from snow will move down into the soil and remain there for quite some time (Yu et al. 2003).

NDVI was influenced not only by climate in the current growing season but also by the growing seasons in the previous years. An approximate 15- to 19-month delay was found between vegetation NDVI and precipitation; this delay covered the entire current growing season ( 7 or 9 months) plus the previous $8-10$ months in the three regions (Fig. 5). Different ranges of temporal lags in vegetation responses to climate change have been widely observed in other regions. Braswell et al. (1997) suggested that NDVI had an approximately 2-year lag response to temperature. Some studies found a 2- to 6-month lag time of NDVI response to climate in China (Piao et al. 2006b), Inner Mongolia (Chuai et al. 2013), and Ansai County on the Loess Plateau (Madelene and Chen 2006) because these studies mainly focused on the current growing season.

Precipitation is generally assumed able to promote vegetation growth; however, the vegetation greening trend has continuously increased during the past 30 years on the Loess Plateau, while precipitation has slightly decreased during the same period. This phenomenon has mainly occurred in semi-arid and semi-humid regions where the Grain for Green Program (GFGP) was launched in 1998. Actually, the temporal pattern of growing-season NDVI is consistent with that of precipitation in the arid region where no GFGP was launched. Both growing-season NDVI and growing-season precipitation increased before TP of growing-season NDVI (1994) (0.0013 year $^{-1}, n=13$, $r=0.6, P<0.05 ; 1.56 \mathrm{~mm} \mathrm{year}^{-1}, r=0.10, P=0.76$, respectively) but significantly decreased after the TP of growing-season NDVI (0.0016 year ${ }^{-1}, r=0.57, n=18$, $P<0.05 ; 1.64 \mathrm{~mm} \mathrm{year}^{-1}, r=0.49, P<0.05$, respectively) in the arid region (Fig. 3 ). Thus, the inverse relationship between growing-season NDVI and precipitation in the semi-arid and semi-humid regions might be due to human activities on the Loess Plateau.

The Loess Plateau is one of the main plateaus in the world; human activities have significantly impacted this region since ancient times (Cai 2002). In particular, reverting farmlands to forests or grasslands during the last decade may have directly affected the vegetation cover of the Loess Plateau. For example, approximately 15 million hectares of cultivated land (slope $>25^{\circ}$ ) and 17 million hectares of abandoned lands have been re-established into seminatural vegetation as a consequence of GFGP in China (Chen et al. 2009). For example, the vegetation cover of northern Shaanxi, which is one of the key regions where GFGP has been recently introduced (Feng et al. 2013), has increased significantly during the growing season after the year $2000\left(R^{2}=0.78, n=12, P<0.001\right) \quad$ (Fig. 6a). Changes in temperature and precipitation, however, did not follow the pattern of NDVI, which continued increasing during the last decade (Fig. 6b). An increase in the accumulated vegetation restoration area, which matched the patterns of elevated NDVI, suggested that elevated NDVI was a product of restoration rather than a climate effect in northern Shaanxi. However, the contributions of human activities to the change in vegetation are difficult to quantify because of the complexity of these mechanisms (Piao et al. 2006b; Xin et al. 2008). Therefore, more in situ observations and validations are necessary to quantitatively assess the impact of anthropogenic activities on local vegetation growth, as well as the interaction between climate alteration and land management practices.
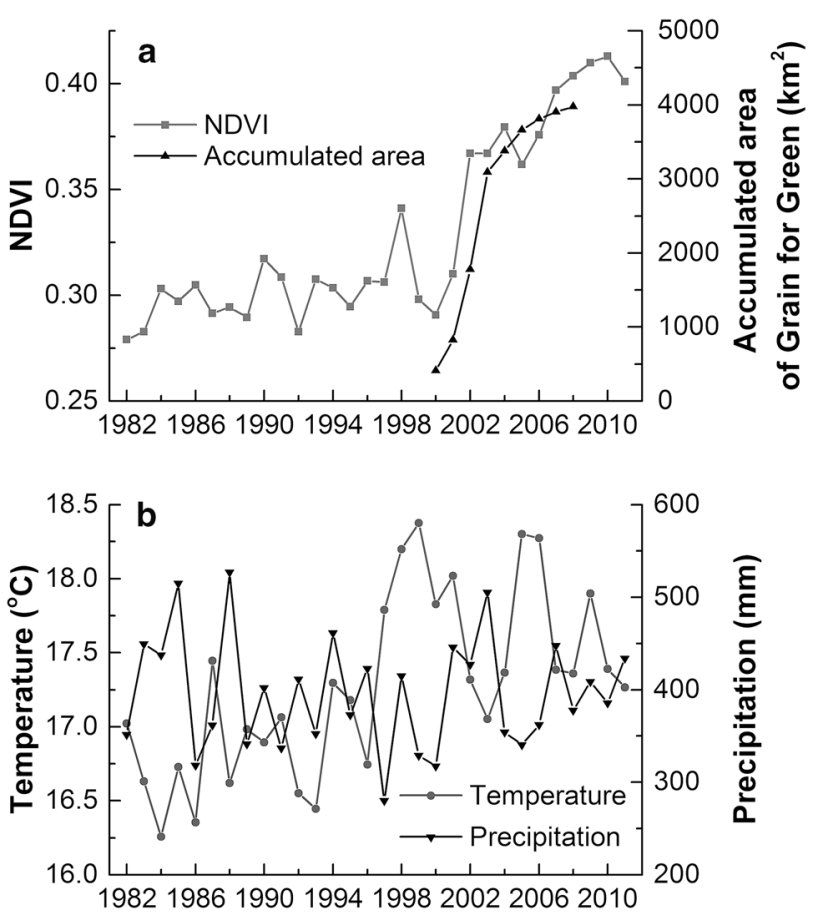

Fig. 6 a Inter-annual variations in NDVI in the growing season and accumulated vegetation construction area and $\mathbf{b}$ temperature and precipitation in the northern Shaanxi in 1982-2011 


\section{Conclusions}

This study analyzed vegetation growth and its response to historical climate change in three climate regions on the Loess Plateau in China during the growing seasons of 1982-2011. In summary, the results presented in this study demonstrated that vegetation growth, which was estimated using NDVI, continuously increased in the semi-arid and semi-humid regions during the study period. In the arid region of the Loess Plateau, however, NDVI increased in 1982-1994 but decreased in 1994-2011. As regards the relationship between vegetation NDVI and climate variables, this study illustrated that vegetation NDVI was sensitive to variations in precipitation in the arid and semiarid regions and to variations in temperature in the semihumid region. Additionally, our results showed that the vegetation growth response to precipitation shifts had a 15to 19-month time lag in all three climate regions. Our results also showed that vegetation growth cannot be fully explained by climate change: Human activities may also have a significant effect on the changes in vegetation cover on the Loess Plateau (Miao et al. 2012; Xin et al. 2008). However, quantifying the contribution of anthropogenic disturbance to vegetation growth remains a great challenge. Future research should therefore reveal the relative contribution of climate and human factors on vegetation.

Acknowledgments This work was supported by the National High Technology Research and Development Program of China (863 Program) (2013AA102401-2); National Key Technology Research and Development Program of the Ministry of Science and Technology of China (2012BAH29B04-00); and National Natural Science Foundation of China (41501233). The authors would like to thank the LTDR project group, NASA Earth Observing System Data Gateway, and National Meteorological Information Centre. The editors and the reviewers of this manuscript are also acknowledged for their insightful comments.

\section{References}

Albert Klein T, Janet W, Aryan van E (2002) Climate of Europe: assessment of observed daily temperature and precipitation extremes. De Bilt, The Netherlands

Alcaraz-Segura D, Liras E, Tabik S, Paruelo J, Cabello J (2010) Evaluating the consistency of the 1982-1999 NDVI trends in the Iberian Peninsula across four time-series derived from the AVHRR sensor: LTDR, GIMMS, FASIR, and PAL-II. Sensors 10:1291-1314. doi:10.3390/s100201291

Barber VA, Juday GP, Finney BP (2000) Reduced growth of Alaskan white spruce in the twentieth century from temperature-induced drought stress. Nature 405:668-673. doi:10.1038/35015049

Braswell BH, Schimel DS, Linder E, Moore B (1997) The response of global terrestrial ecosystems to interannual temperature variability. Science 278:870-872. doi:10.1126/science.278.5339.870

Cai QG (2002) The relationship between soil erosion and human activities on the Loess Plateau. In: Proceedings of the 12th international soil conservation organisation conference, pp 26-31
Cai F, Yu G, Zhu Q, He H, Liu X, Li Z, Guo X (2005) Comparison of precisions between spatial methods of climatic factors: a case study on mean air temperature. Resour Sci 27:173-179 (in Chinese with English abstract)

Cao MK, Woodward FI (1998) Dynamic responses of terrestrial ecosystem carbon cycling to global climate change. Nature 393:249-252. doi:10.1038/30460

Chen XG, Zhang XQ, Zhang YP, Wan CB (2009) Carbon sequestration potential of the stands under the Grain for Green Program in Yunnan Province, China. For Ecol Manag 258:199-206. doi:10.1016/j.foreco.2008.07.010

Chuai XW, Huang XJ, Wang WJ, Bao G (2013) NDVI, temperature and precipitation changes and their relationships with different vegetation types during 1998-2007 in Inner Mongolia, China. Int J Climatol 33:1696-1706. doi:10.1002/joc.3543

Cleland EE, Chuine I, Menzel A, Mooney HA, Schwartz MD (2007) Shifting plant phenology in response to global change. Trends Ecol Evol 22:357-365. doi:10.1016/j.tree.2007.04.003

Cong N, Wang T, Nan H, Ma Y, Wang X, Myneni RB, Piao S (2013) Changes in satellite-derived spring vegetation green-up date and its linkage to climate in China from 1982 to 2010: a multimethod analysis. Global Change Biol 19:881-891. doi:10.1111/gcb. 12077

Dai SP, Zhang B, Wang HJ, Wang YM, Guo LX, Wang XM, Li D (2011) Vegetation cover change and the driving factors over northwest China. J Arid Land 3:25-33. doi:10.3724/sp.j.1227. 2011.00025

De Jong R, Verbesselt J, Schaepman ME, de Bruin S (2012) Trend changes in global greening and browning: contribution of shortterm trends to longer-term change. Global Change Biol 18:642-655. doi:10.1111/j.1365-2486.2011.02578.x

Feng XM, Fu BJ, Lu N, Zeng Y, Wu BF (2013) How ecological restoration alters ecosystem services: an analysis of carbon sequestration in China's Loess Plateau. Sci Rep. doi:10.1038/ srep02846

Gong DY, Shi PJ (2003) Northern hemispheric NDVI variations associated with large-scale climate indices in spring. Int J Remote Sens 24:2559-2566. doi:10.1080/0143116031000075107

Han XW, Tsunekawa A, Tsubo M, Li SQ (2010) Effects of landcover type and topography on soil organic carbon storage on Northern Loess Plateau, China. Acta Agr Scand B Plant 60:326-334. doi:10.1080/09064710902988672

Holben BN (1986) Characteristics of maximum-value composite images from temporal AVHRR data. Int J Remote Sens 7:1417-1434. doi:10.1080/01431168608948945

Jeong SJ, Ho CH, Gim HJ, Brown ME (2011) Phenology shifts at start vs. end of growing season in temperate vegetation over the Northern Hemisphere for the period 1982-2008. Global Change Biol 17:2385-2399. doi:10.1111/j.1365-2486.2011.02397.x

Jobbagy EG, Sala OE, Paruelo JM (2002) Patterns and controls of primary production in the Patagonian steppe: a remote sensing approach. Ecology 83:307-319. doi:10.2307/2680015

Keeling CD, Chin JFS, Whorf TP (1996) Increased activity of northern vegetation inferred from atmospheric $\mathrm{CO}_{2}$ measurements. Nature 382:146-149. doi:10.1038/382146a0

Kimball JS, McDonald KC, Running SW, Frolking SE (2004) Satellite radar remote sensing of seasonal growing seasons for boreal and subalpine evergreen forests. Remote Sens Environ 90:243-258. doi:10.1016/j.rse.2004.01.002

Kurtzman D, Kadmon R (1999) Mapping of temperature variables in Israel: a comparison of different interpolation methods. Clim Res 13:33-43. doi:10.3354/cr013033

Lucht W, Prentice IC, Myneni RB, Sitch S, Friedlingstein P, Cramer W, Bousquet P, Buermann W, Smith B (2002) Climatic control of the high-latitude vegetation greening trend and Pinatubo effect. Science 296:1687-1689. doi:10.1126/science.1071828 
Madelene OA, Chen DL (2006) Land-use change: impacts of climate variations and policies among small-scale farmers in the Loess Plateau, China. Land Use Policy 23:361-371. doi:10.1016/j. landusepol.2005.04.004

Miao CY, Yang L, Chen XH, Gao Y (2012) The vegetation cover dynamics (1982-2006) in different erosion regions of the Yellow River Basin, China. Land Degrad Dev 23:62-71. doi:10.1002/ ldr. 1050

Mohammat A et al (2013) Drought and spring cooling induced recent decrease in vegetation growth in Inner Asia. Agric For Meteorol 178:21-30. doi:10.1016/j.agrformet.2012.09.014

Myneni RB, Keeling CD, Tucker CJ, Asrar G, Nemani RR (1997) Increased plant growth in the northern high latitudes from 1981 to 1991 . Nature $386: 698-702$. doi: $10.1038 / 386698 \mathrm{a} 0$

Nemani RR et al (2003) Climate-driven increases in global terrestrial net primary production from 1982 to 1999 . Science 300:1560-1563. doi:10.1126/science. 1082750

Paruelo JM, Lauenroth WK (1995) Regional patterns of normalized difference vegetation index in North-American shrublands and grasslands. Ecology 76:1888-1898. doi:10.2307/1940721

Pedelty J, Devadiga S, Masuoka E, Brown M, Pinzon J, Tucker C, Roy D, Ju JC, Vermote E, Prince S, Nagol J, Justice C, Schaaf C, Liu JC, Privette J, Pinheiro A (2007) Generating a long-term land data record from the AVHRR and MODIS instruments. Barcelona, Spain

Piao SL, Fang JY, Ji W, Guo QH, Ke JH, Tao S (2004) Variation in a satellite-based vegetation index in relation to climate in China. J Veg Sci 15:219-226

Piao SL, Fang JY, Zhou LM, Ciais P, Zhu B (2006a) Variations in satellite-derived phenology in China's temperate vegetation. Global Change Biol 12:672-685. doi:10.1111/j.1365-2486.2006.01123.x

Piao SL, Mohammat A, Fang JY, Cai Q, Feng JM (2006b) NDVIbased increase in growth of temperate grasslands and its responses to climate changes in China. Global Environ Change 16:340-348. doi:10.1016/j.gloenvcha.2006.02.002

Piao S, Wang X, Ciais P, Zhu B, Wang TAO, Liu JIE (2011) Changes in satellite-derived vegetation growth trend in temperate and boreal Eurasia from 1982 to 2006. Global Change Biol 17:3228-3239. doi:10.1111/j.1365-2486.2011.02419.x

Prentice IC, Cramer W, Harrison SP, Leemans R, Monserud RA, Solomon AM (1992) A global biome model based on plant physiology and dominance, soil properties and climate. J Biogeogr 19:117-134. doi:10.2307/2845499

R Core Team (2015) R: A language and Environment for Statistical Computing. R Foundation for Statistical Computing, Vinena, Austria. http://www.R-project.org/

Shi H, Shao MG (2000) Soil and water loss from the Loess Plateau in China. J Arid Environ 45:9-20. doi:10.1006/jare.1999.0618

Tucker CJ (1979) Red and photographic infrared linear combinations for monitoring vegetation. Remote Sens Environ 8:127-150. doi:10.1016/0034-4257(79)90013-0

Tucker CJ, Dregne HE, Newcomb WW (1991) Expansion and contraction of the Sahara Desert from 1980 to 1990. Science 253:299-301. doi:10.1126/science.253.5017.299
Verbyla D (2008) The greening and browning of Alaska based on 1982-2003 satellite data. Global Ecol Biogeogr 17:547-555. doi:10.1111/j.1466-8238.2008.00396.x

Vermote EF, Saleous NZ (2006) Calibration of NOAA16 AVHRR over a desert site using MODIS data. Remote Sens Environ 105:214-220. doi:10.1016/j.rse.2006.06.015

Wang J, Rich PM, Price KP (2003) Temporal responses of NDVI to precipitation and temperature in the central Great Plains, USA. Int J Remote Sens 24:2345-2364. doi:10.1080/01431160210154812

Wang Z, Suo Y, Lin X, Shi R (2008) Advances in AVHRR Global Time Serials: PAL-GIMMS-LTDR. Resour Sci 30:1252-1260 (in Chinese with English abstract)

Wang XH, Piao SL, Ciais P, Li JS, Friedlingstein P, Koven C, Chen AP (2011a) Spring temperature change and its implication in the change of vegetation growth in North America from 1982 to 2006. Proc Natl Acad Sci USA 108:1240-1245. doi:10.1073/ pnas. 1014425108

Wang YQ, Shao MA, Zhu YJ, Liu ZP (2011b) Impacts of land use and plant characteristics on dried soil layers in different climatic regions on the Loess Plateau of China. Agric For Meteorol 151:437-448. doi:10.1016/j.agrformet.2010.11.016

Wang Q, Fan X, Qin Z, Wang M (2012) Change trends of temperature and precipitation in the Loess Plateau Region of China, 1961-2010. Global Planet Change 92-93:138-147. doi:10. 1016/j.gloplacha.2012.05.010

Xin ZB, Xu JX, Zheng W (2008) Spatiotemporal variations of vegetation cover on the Chinese Loess Plateau (1981-2006): impacts of climate changes and human activities. Sci China Ser D 51:67-78. doi:10.1007/s11430-007-0137-2

Wu ZY (1982) Vegetation of China. Science Press, Beijing (in Chinese)

Yu F, Price KP, Ellis J, Shi P (2003) Response of seasonal vegetation development to climatic variations in eastern central Asia. Remote Sens Environ 87:42-54. doi:10.1016/S0034-4257(03)00144-5

Zhang JT, Ru WM, Li B (2006) Relationships between vegetation and climate on the Loess Plateau in China. Folia Geobot 41:151-163. doi: $10.1007 / \mathrm{bf} 02806476$

Zhang GL, Zhang YJ, Dong JW, Xiao XM (2013) Green-up dates in the Tibetan Plateau have continuously advanced from 1982 to 2011. Proc Natl Acad Sci USA 110:4309-4314. doi:10.1073/ pnas. 1210423110

Zhao X, Tan K, Zhao S, Fang J (2011) Changing climate affects vegetation growth in the arid region of the northwestern China. J Arid Environ 75:946-952. doi:10.1016/j.jaridenv.2011.05.007

Zheng J, Yin Y, Li B (2010) A new scheme for climate regionalization in China. Acta Geogr Sin 65:4-12 (in Chinese with English abstract)

Zhou ZC, Shangguan ZP, Zhao D (2006) Modeling vegetation coverage and soil erosion in the Loess Plateau Area of China. Ecol Model 198:263-268. doi:10.1016/j.ecolmodel.2006.04.019 